\title{
The Losses in the Rice Harvest Process: A Review
}

\author{
Xue $Q u^{1, *}$, Daizo Kojima ${ }^{1}$, Laping $W^{2}{ }^{2}$ and Mitsuyoshi Ando ${ }^{1}$ \\ 1 Department of Agricultural and Resource Economics, The University of Tokyo, Tokyo 113-8657, Japan; \\ akojima@g.ecc.u-tokyo.ac.jp (D.K.); ando@g.ecc.u-tokyo.ac.jp (M.A.) \\ 2 College of Economics and Management, China Agricultural University, 17 Qinghua East Road, \\ Haidian District, Beijing 100083, China; wulp@cau.edu.cn \\ * Correspondence: quxue@g.ecc.u-tokyo.ac.jp
}

check for

updates

Citation: Qu, X.; Kojima, D.; Wu, L.; Ando, M. The Losses in the Rice

Harvest Process: A Review.

Sustainability 2021, 13, 9627.

https://doi.org/10.3390/su13179627

Academic Editor: Riccardo Guidetti

Received: 30 June 2021

Accepted: 19 August 2021

Published: 26 August 2021

Publisher's Note: MDPI stays neutral with regard to jurisdictional claims in published maps and institutional affiliations.

Copyright: (c) 2021 by the authors. Licensee MDPI, Basel, Switzerland. This article is an open access article distributed under the terms and conditions of the Creative Commons Attribution (CC BY) license (https:// creativecommons.org/licenses/by/ $4.0 /)$.

\begin{abstract}
We review existing studies on rice harvest loss from the aspects of estimation methods, magnitudes, causes, effects, and interventions. The harvest losses examined occurred from the field reaping to storage processes, including threshing, winnowing, and field transportation. We find that existing studies on rice harvest losses have focused on quantitative losses in Asia and Africa. Lack of knowledge, inadequate harvesting techniques, poor infrastructure, and inefficient harvest management practices are considered critical contributors to the losses. The magnitudes and causes of rice harvest losses are now better understood than interventions, which have simply been presented but lack an assessment of the effects and a cost-benefit analysis. Interestingly, reduction in harvest losses may threaten some farmers' profits, such as rural women who make their living from post-production manual operations. Considering the current status of the literature, future researchers should examine how to balance social and individual welfare since farmers are key stakeholders in intervention implementation. A good understanding of the existing researches can help clarify future efforts for loss reduction, thereby reducing the burden of increasing agricultural production and promoting sustainable development of resources and the environment.
\end{abstract}

Keywords: farming; review; harvest loss; farm loss

\section{Introduction}

According to the Food and Agriculture Organization of the United Nations (FAO), food production will have to increase by $70 \%$ to feed the world's projected 9.1 billion population by 2050 [1]. For a long time, the dominant view for improving future food supply has been to increase food production; however, this would not achieve the world's growing agricultural demand in an environmentally sustainable manner [2]. Agriculture imposes huge resource and environmental costs in terms of land, water, and greenhouse gas emissions, among others [3]. Research has identified significant food wastage (both food loss and food waste). Thus, reducing food wastage is a critical way to increase the food supply [4-7] without incurring substantial environmental costs [8].

Vast amounts of resources are used to produce, process, and transport food. If this food does not end up being consumed, the resources embedded in the process are wasted and cause environmental degradation [2,9-11]. It is estimated that nearly a quarter of the water, arable land, and fertilizer used globally for food crop production is associated with food wastage [6]. In 2010, China's food waste accounted for more than $10 \%$ of the country's total water use [12]. Such a loss in China means about 26.11 million hectares of land were used in vain, which is equal to Mexico's total arable land [13]. With global food wastage causing 3.3 Gtonnes of carbon dioxide emissions, if regarded as a country, food wastage would be the third top emitter, after the United States and China [14]. Reducing food wastage not only increases the food supply and reduces pressure to increase production, but also saves resources and reduces environmental damage. After the food crisis of the early 1970s, preventing food wastage has been widely recognized as a solution to the 
world's food problems [15,16]. In 2015, the United Nations stated the following aim: "by 2030, halve the per capita global food waste at the retail and consumer level, and reduce food losses along production and supply chains including post-harvest losses" [17]

Food wastage occurs at every stage from the farm to the fork, including in production, reaping, processing, transportation, marketing, and consumption [18-21]. The mechanisms of food wastage differ at each stage. A distinction is therefore made between food loss, which occurs at the front end of the supply chain (mainly at production and distribution levels), and food waste, which occurs at its back end (mainly at the consumption level) [22,23]. Specifically, food loss refers to "a decrease in mass (dry matter) or nutritional value (quality) of food that was originally intended for human consumption," while food waste means "food appropriate for human consumption being discarded, whether or not after it is kept beyond its expiry date or left to spoil" [14] (pp. 8-9). Food loss is dominant in developing countries because it is mainly caused by technical limitations, such as inadequate harvest techniques, poor infrastructure and logistics, lack of storage facilities, and insufficient skills and management $[14,24,25]$. The proportion of food waste is low in developing countries because consumers buy food as needed [22] and waste is not socially acceptable owing to the relatively high poverty levels [21]. In contrast, agricultural systems in developed countries are more efficient, with better transportation infrastructure and more effective storage facilities, resulting in a lower proportion of food loss [26]. However, food waste is more serious in these countries owing to consumers' excessive consumption habits or high standards of food selection [24,27]. Some fast-growing transition countries, such as China, have recorded high loss and waste at both the front and back ends of the value chain [4].

Owing to differences in definitions and measurement methods [28], the exact magnitude of food loss and waste remains uncertain $[29,30]$. Estimates vary substantially according to crop, stage in the value chain, region, and so on [20,31]. Therefore, global estimates of loss and waste that ignore these heterogeneities are questioned [31,32]. Estimating the food loss and waste over a wide range (e.g., across regions or supply chain stages) is difficult and meaningless as reduction interventions need to be adapted to regions, stakeholders, and local contexts [2]. As mentioned earlier, developing countries suffer more food losses than food waste. The reduction in income due to food losses is a great threat to farm households in these countries that are already on the verge of food insecurity. Reducing food losses in developing countries is more urgent. Therefore, this study reviewed the researches on food loss while restricting the crops to rice, the stakeholders to farmers, and the supply chain stage to the harvesting process.

As one of the world's three leading food crops, rice feeds almost half of the world's population, making it the most consumed cereal grain [33], especially in low- and lowermiddle-income countries [34]. Among rice farmers, processors, and marketers, rice farmers experience the highest loss $[35,36]$. Losses on farms reduce farmers' incomes, and for farmers in low-income countries living on the edge of hunger, these losses are closely associated with food insecurity [37,38]. Most of the produce is lost during post-harvest handling and on-farm storage $[7,22]$. The harvest marks the beginning of the cereal supply chain [27] and is the decisive step in determining the yield quality [39] and the subsequent storage quality [40]. The proportion of cereal lost during the harvest process is higher than farm losses at other stages [41], with most farmers losing a considerable amount of cereal during this process [42]. However, over $80 \%$ of existing studies focus specifically on on-farm storage loss [29], which means less attention has been paid to losses during the harvest process.

Harvesting operations occur on the field and consist of cutting the stalks or reaping the panicles and bundling for transportation [36]. Cutting or reaping is done by knife, serrated sickle, paddy mower, reaper, or combine harvester [43]. In developing countries, harvesting is mainly done using traditional hand tools (i.e., knife and serrated sickle) $[38,39]$, which are considered inefficient practices [44]. Traditional practices were considered ineffective, not because of the clear evidence of high loss, but because they were distinguished by "ancient" activities uninfluenced by contemporary technology [16]. Harvest loss mainly 
manifests as physical loss [45]. When cutting or reaping the straws, grains may be scattered across the field, plowed into the soil, and eaten by birds and rodents [23]. However, Qu and colleagues [45] noted that the use of combine harvesters weakens the delineation between the post-processing stages of rice (i.e., reaping, threshing, and winnowing) compared to manual operations, making it difficult to strictly distinguish the losses that occur at these stages. Therefore, they defined the process from field reaping to on-farm storage places as the harvesting process and estimated the harvest loss during this process divided into four stages: reaping, threshing, winnowing, and field transportation. Consequently, the studies on rice harvest loss we reviewed are not only limited to reaping loss, but also include threshing, winnowing, and field transportation loss. Threshing is the process of removing the paddy kernels or grains from the panicles [36,39]. This operation could be done by trampling, banging, pedal thresher, power thresher, and combine harvester [43]. Threshing loss refers to grains remained on the panicles or scattered on the threshing floor [45]. After threshing, the immature grains, rice straw, stones, sand, chaff, and other foreign materials are removed from the threshed paddy by sieving or wind [46], during which paddy may also be removed, resulting in winnowing loss [38]. Field transportation refers to transferring the grain from the field or winnowing places to warehouses, and loss may be caused by spillage $[39,45]$.

Reducing food losses as another crucial way of increasing food supply in addition to increasing production can be beneficial to resource sustainability by not increasing resource inputs and by saving resources already invested. The overarching goal of this review is to analyze the existing researches on rice harvest loss, including the loss that occurs during reaping, threshing, winnowing, and field transportation. We focused on the estimating techniques of harvest loss as well as its extent, causes, effects, and interventions. Overall, this review summarizes the current status and shortcomings of existing rice harvest loss researches and identifies future efforts for loss reduction. In the remainder of this review, we first introduce the method of this research. We then present the main findings. Lastly, we identify the key knowledge gaps and possibilities for future research.

\section{Materials and Methods}

We reviewed the researches on rice harvest loss by accessing both peer-reviewed articles and national and international reports (e.g., FAO and World Bank) through multiple major databases (e.g., Web of Science, Google Scholar, Scopus, Semantic Scholar, and China National Knowledge Infrastructure), though peer-reviewed articles were preferred. Searched keywords included "food loss" OR "food waste" OR "grain loss" OR "grain waste" OR "crop loss" OR "crop waste" OR "rice loss" OR "harvest loss" OR "post-harvest loss" OR "lost food". Strictly speaking, losses during harvesting are post-production rather than post-harvest losses. However, harvesting is often considered the starting point of the post-harvest management process, and existing studies do not strictly distinguish these stages, so we use "postharvest" for retrieval. In addition, we performed supplemental searches for additional sources by reviewing article bibliographies. The last search was performed in August 2021.

Articles were screened for eligibility using the following inclusion criteria: (1) published in English or Chinese; (2) published in the social sciences rather than the natural sciences or engineering; and (3) estimated the food loss rather than the food waste; (4) estimated the rice harvest loss (or reaping loss, threshing loss, winnowing loss, and field transportation loss) or corresponding causes, impacts, and interventions. After removal of duplicates and the above four inclusion criteria, we then excluded unrelated articles by scanning the titles and abstracts and full-text reading. Finally, we screened 64 studies, including 37 studies that estimated rice harvest losses (Table 1). 


\section{Results}

\subsection{Estimation Methods}

The first step in reducing losses is to estimate the magnitudes in each stage. Postharvest losses in rice may be quantitative or qualitative. Quantitative losses result in weight or volume reduction in the potential yield, while qualitative losses result in a reduction in the value of the usable rice owing to physical and chemical changes, such as poor appearance, poor taste, and unpleasant odor [35]. Nonetheless, harvest losses are usually measured as actual physical losses (i.e., quantitative losses). This is partly because qualitative losses are more difficult to measure than quantitative ones [47], and partly because there is often not enough quality awareness to distinguish between grades of rice before it reaches the formal market [48].

Existing studies have taken two main approaches to estimate harvest losses: either by direct measuring what is lost or by using questionnaires to obtain subjective estimates from rice farmers [4]. Direct measurement of losses is usually done by conducting rice harvest experiments in the field and then collecting and weighing the lost rice [49]. Before conducting the experiment, rice losses at each stage need to be clearly determined. The assessment of rice losses from reaping, threshing, winnowing, and field transportation in field experiments is discussed below.

\subsubsection{Rice Loss during Reaping}

Reaping is done by manual or mechanical methods, and the form of loss varies depending on the harvesting method. There are usually two harvesting methods: combine harvesting (i.e., head-feed and whole-feed) and segmented harvesting (manual reaping and reaper plus manual threshing or thresher) [45]. Alizadeh and Allameh [50] referred to them as indirect harvesting and direct harvesting, respectively. When using segmented harvesting, the losses in the reaping stage include scattering loss and uncut loss [48,51,52]. Scattering loss occurs when rice grains fall in the field as a result of touching or other external forces owing to the influence of various aspects such as harvesting method, crop variety, and maturity when cutting the straw or panicle. Uncut loss occurs when the straw or panicle is not cut because of careless working, lodging, and other reasons. To determine the scattering loss and uncut loss, grains on the ground and the uncut straw or panicle in the sample frame $(1 \mathrm{~m} \times 1 \mathrm{~m}$ or other sizes) or experimented plots are collected and weighed $[50,51,53]$. If the cut straw directly moves to the next threshing operation, then the reaping loss is limited to the description above. However, in some regions, the cut straw is laid in the field for a few days before threshing and bundled for transportation to the homestead or threshing yard [54]. The grains that fall into the field during these days also count as the loss during reaping, or, in other words, stacking loss and bundling loss [55,56]. To assess these losses, plastic sheets are placed under the grain stacks, and the grain that falls on the sheets is collected later for counting [48,53,57].

When using combine harvesters, there is no stacking loss or bundling loss-only scattering loss and uncut loss. Since these harvesters complete the following threshing and winnowing operations at once, the loss here also includes the threshing and winnowing losses described below [50]. Although Hasan and colleagues [58] considered combine harvesting loss to also include cutter bar loss and cylinder loss, they only estimated the total loss. After the completion of combine harvesting, suitable sample frames $(1 \mathrm{~m} \times$ $1 \mathrm{~m}$ or other sizes) are randomly selected in the harvested fields. To estimate the loss, the dropped grains in the field and uncut straws from the sample area are collected and weighed for counting $[50,56]$.

\subsubsection{Rice Loss during Threshing}

Threshing could also be done by manual or mechanical methods. Manual threshing is done by the grain flail and threshing board or rack in Bangladesh [36], bag-beating and "bambam" (a wooden box) in Ghana [59], and pedal thresher in China [43]. Mechanical threshing employs power threshers and combine harvesters $[43,60]$. Regardless of the 
method, losses during threshing are broadly divided into scattering loss and unthreshed loss $[48,51]$. Manual or mechanical efforts to separate paddy from panicles can result in scattered or spilled rice, leading to scattering loss. After threshing, the rice grains that fall outside the plastic sheets or wooden boxes are collected and weighed [51,59]. Unthreshed loss refers to the grain remaining on the seed head. Assessment of this remaining grain can be done by taking a random sample of straws after threshing and separating the grains on the straws and weighing them $[48,51,57,61]$.

\subsubsection{Rice Loss during Winnowing}

Loss during winnowing refers to the grain discarded with the straw and external impurities. A suitable sample of straws after winnowing is taken, and the grains blown away with the straw are separated and weighed [56].

\subsubsection{Rice Loss during Field Transportation}

Losses during transportation in the field are mainly owing to broken packaging, which causes grains to fall to the ground. Measuring losses during transportation requires careful collection of scattered grains or weighing of grain bags at both the start and end of the transportation process $[48,53]$.

Estimates from direct measurements may be more accurate but are time- and resourceconsuming [62]. Another commonly used estimation method is the questionnaire survey. Farmers experiencing losses are surveyed using a carefully designed structured questionnaire to elicit their estimates [4]. The accuracy of farmers' self-report data may be questioned compared to direct measurements. However, there is no actual evidence that farmers' measurement errors are larger than the errors in other estimates. Thus, farmer self-reports obtained based on well-designed questionnaires are considered reliable estimates [20]. However, Kannan [63] believed that farmer estimates may be subjective and are best validated by experts. In addition, some estimation methods are rarely used, such as direct observation [54] and modeling [62], which were not observed in the studies we reviewed.

\subsection{Magnitude of the Harvest Loss}

It is difficult to present a definite figure on rice harvest losses owing to differences in regions, harvesting methods, and varieties, among others. Even in the same region, there can be significant differences by season. Therefore, it is not realistic to describe rice harvest losses with a single figure. The estimation of losses then requires a situation-specific analysis [54]. Thus, rather than attempting to derive an exact loss figure from the reviewed studies, we attempted to determine some characteristics of these data. 
Table 1. Harvest losses in some countries and regions.

\begin{tabular}{|c|c|c|c|}
\hline Cot & es or Regions & Harvest Losses & Citation(s) \\
\hline \multirow{4}{*}{ Africa } & Nigeria & $\begin{array}{l}\text { Quantitative loss: } 4.84-9.73 \% \\
\text { Economic loss: } 230.11 \text { billion naira }\end{array}$ & {$[37,38,51,64]$} \\
\hline & Ghana & $\begin{array}{l}\text { Quantitative loss: } 3.57-16.14 \% \\
\text { Economic loss: } 64.79 \mathrm{GHC}\end{array}$ & {$[59,60,65,66]$} \\
\hline & Sub-Sahara Africa & Quantitative loss: $7.9-13.1 \%$ & [67] \\
\hline & Egypt & Quantitative loss: $1.35-2.49 \%$ & {$[53]$} \\
\hline \multirow{8}{*}{ Asia } & India & $\begin{array}{l}\text { Quantitative loss: } 1.60-5.95 \mathrm{~kg} / \text { quintal; } \\
2.88-3.60 \%\end{array}$ & {$[56,68-75]$} \\
\hline & China & Quantitative loss: $1.23-5.5 \%$ & {$[45,52,55,76-80]$} \\
\hline & Bangladesh & Quantitative loss: 1.61-6.95\% & {$[36,57,58,61,81,82]$} \\
\hline & Iran & $\begin{array}{l}\text { Quantitative loss: } 2.26-2.58 \% \\
\text { Qualitative loss: } 0.47-2.44 \%\end{array}$ & {$[50]$} \\
\hline & Myanmar & $\begin{array}{l}\text { Quantitative loss: } 16.0-28.2 \% \text { (wet season); } \\
0.9-9.3 \% \text { (dry season) }\end{array}$ & {$[49,55]$} \\
\hline & Thailand & Quantitative loss: 1.1-9.3\% & [55] \\
\hline & Indonesia & Quantitative loss: $8.26-8.83 \%$ & [83] \\
\hline & $\begin{array}{l}\text { Democratic Republic of } \\
\text { Timor-Leste }\end{array}$ & $\begin{array}{l}\text { Quantitative loss: } 10.15 \% \\
\text { Economic loss: USD } 9100\end{array}$ & [54] \\
\hline North America & Dominican Republic & Quantitative loss: $12.27-24.82 \%$ & [84] \\
\hline
\end{tabular}

Note: See Appendix A Table A1 for more details.

Table 1 presents the ranges of harvest losses for some countries or regions. Among the studies we reviewed, only one was conducted in North America [84], while the rest examined the Asian and African regions, with more than $70 \%$ focused on Asia. Most studies expressed the magnitude of quantitative loss as a percentage, and a few used the absolute weight of loss $[37,68,69]$ and market value $[38,54,60]$, while only one study measured qualitative losses [50]. The losses in reaping and threshing are larger than those in winnowing and field transportation $[51,64]$.

Preliminary data obtained from rice harvesting trials indicate absolute loss in terms of the actual weight of grains. A more common form of quantitative loss is percentage loss [85], which makes comparisons easier [45]. However, different studies calculated the loss percentage with different denominators. Some used the remaining amount in the previous stage as the denominator [85], while others chose the final weight of collected grains at the present stage as the denominator [51,59]. In some, potential yield-the sum of final collected grain and losses-was used as the denominator [45]. However, even if the expressions for losses are the same, losses from different studies, conducted in different regions, seasons, and varieties, cannot be compared [59]. We can still see that most countries or regions in Table 1 have a harvest loss rate of less than $10 \%$.

Traditional manual operations are inefficient [44], which could cause higher losses. The loss due to the use of combine harvesters is smaller than that caused by manual reaping and threshers in Egypt [53]. Similar results were found in Bangladesh [58], Myanmar [49], Dominican Republic [84], and Thailand [55]. However, some findings were contrary. Amusat and colleagues [51] found that mechanical operation causes higher losses at all three stages of reaping, threshing, and winnowing in Nigeria. In particular, threshing loss due to mechanical threshing is more than twice that caused by manual threshing. This is consistent with the findings of the questionnaire survey by Basavaraja and colleagues [74]. Several studies in China, including two field trials [52,79], one farmer survey [45], and a three-year International Development Research Centre survey [55], indicated that losses due to combine harvesting are higher than the total losses from segmented harvesting. 
Compared to manual operation, harvesting loss due to combine harvester use is not only influenced by mechanical performance, but also by operators' skill and the land terrain. Operators of combine harvesters may speed up the process to increase the area harvested per unit of time, leading to a high number of uncut plants and thus increasing the loss $[77,81]$. Since combine harvesters cannot work effectively on land with excessive surface undulations, poor plot topography can greatly affect the work of the machinery [47]. Rice lodging can also make mechanical harvesting difficult and lead to increased losses [79]. However, a rice harvesting trial in Iran by Alizadeh and Allameh [50] showed that there was no significant difference in quantitative loss between combine and segmented harvesting, while the qualitative loss owing to broken, husked, and cracked grains was significantly less in combine harvesting. If the losses due to manual and mechanical operations are compared in one particular stage, the reaping loss caused by reaper use is greater than that by manual reaping in Bangladesh [81], and the threshing loss caused by mechanical threshing is higher than that by manual threshing in Nigeria [51], India [74], Bangladesh [82], and China [55]. However, the winnowing loss due to mechanical winnowers is less than that due to manual operations [70].

Even in manual operation, the loss varies with different methods. Field experiments showed that the reaping loss due to panicle harvesting $(1.38 \%)$ was less than that due to sickle harvesting $(2.93 \%)[59,66]$. Threshing loss was higher using "bambam" than bagging $[59,60,66]$. Transportation loss also varied by transportation method $[63,68,69,76]$.

Furthermore, it was evident from the available researches data that losses varied with rice varieties, harvesting season, and farm size. High-yield varieties incur greater losses than local varieties in reaping, threshing, and winnowing [69], causing an unfortunate tradeoff for farmers [20]. High yields increase the pressure of reaping and threshing operations owing to increased yields, especially when there is a lack of machinery. Additionally, the thin husk and shells of high-yield rice make it more vulnerable to damage during the harvesting process [61]. Early or delayed harvesting can lead to higher loss [71,73]. Overall, the average harvest loss was smaller for large-scale farmers than for small-scale farmers $[68,70,80]$.

\subsection{Causes of Harvest Loss}

Some studies used questionnaires to directly inquire farmers' understanding of the causes of rice harvest losses $[37,47,65,86]$. Multiple regression analyses were also applied to estimate the influencing factors of the losses $[45,74,77,80,82]$. Factors that contribute to harvest losses include environmental, socio-economic, and mechanical [65].

The most important aspect of crop production is the time: excessively early or late harvesting can lead to increased losses [87]. If harvested too early, immature grains can make threshing difficult, resulting in more unthreshed loss [88]. Delayed harvesting may also cause substantial loss owing to shattering and extended exposure to natural incidents, such as attacks by birds and other pests $[49,58,59]$, which is in line with farmers' perspectives [47]. Regression analyses in China confirmed that harvesting in time could reduce harvest loss [77].

A large family could reduce the drudgery involved in harvesting activities and thus reduce harvest losses [89]. Manual harvesting is highly labor-intensive and tedious [90]. If there is not enough labor or access to proper harvesting machinery, the mature rice cannot be harvested in time, causing massive losses $[7,39,49,54,87]$. The significance of this factor was confirmed in the regression analysis $[45,74,77,82]$.

Farm size also affects the magnitude of losses. Some studies concluded that largescale farms record smaller losses per unit area than small-scale farms owing to the use of machinery in China [77] and Bangladesh [82]. However, the opposite results have also been observed in India [74].

Losses are sometimes a result of farmers' choices. For example, harvest losses are often greater using machinery than manual operations. However, owing to the lack of sufficient agricultural labor, farmers will not forgo the use of machinery or other faster 
harvesting methods to reduce losses owing to the growing labor cost, especially for largescale farmers [59]. Soybean farmers in Brazil increase the forward speed of harvesters to maximize profits by harvesting earlier in the first season to leave time for the second season, although they are clearly aware of the higher losses involved [91].

\subsection{Impact of Harvest Loss}

The most straightforward impact of rice harvest losses is a reduction in the amount of edible rice, resulting in economic losses and threatening poor people's livelihoods, especially in less-developed countries [54,90,92]. Farmers believe rice harvest losses threaten their food security and thus lead to poverty [47]. In Bangladesh, Begum and colleagues [82] explored the impact of rice harvest loss on farmers' household food security using logistic regression analysis and found that harvest loss has negative and significant relationships with households' probability of food security. Multiple regression analyses showed that rice threshing losses had a significantly negative impact on farmers' income in Nigeria [37].

The impact of these losses on the resource environment has been much discussed. However, there are few specific measurements of the environmental and resource impacts. In Nigeria, the loss of rice from production to milling results in the waste of 2.1 million $\mathrm{m}^{3}$ of water, 0.5 million hectares of land, and the emission of about 0.65 million tons of carbon dioxide equivalent per year [64]. The loss of rice from reaping to milling in Myanmar leads to an increase in greenhouse gas emissions of about $30-50 \%$ per hectare of rice production [49].

\subsection{Interventions}

Based on the above discussion, some common interventions targeting the reduction in rice harvest losses include improving infrastructure, introducing advanced machinery and equipment, timely harvesting, providing training to farmers, and strengthening pest and disease management $[63,72-74,93]$. However, proposing interventions is only the first step: What is more important is whether the interventions can be effectively implemented by farmers $[7,19]$, whether they have significant effects $[19,20,92,94]$, and whether cost-benefit analysis presents important results $[19,20,47]$.

Loss interventions should be designed from the perspective of farmers' profits. Whether farmers adopt new technologies and invest in loss reduction is primarily motivated by maximizing household profits, not production [20,44,61]. Although the results of some studies showed that losses in manual operation are lower, this does not mean that manual handling should be encouraged, because if manual operation is delayed owing to the lack of labor, it may lead to greater losses. As farm labor becomes scarce, harvesters and threshers, or combine harvesting, must be used. There is a trade-off between the need for mechanization and its associated higher losses [59]. Soybean farmers in Brazil derive additional time for second season production by harvesting the first season crop quickly [91]. If farmers are persuaded to reduce their harvesting speed to reduce losses, they may not be receptive because it would reduce their profitability. Hybrids and high-yield varieties are more likely to lead to post-harvest losses [20], but this does not mean farmers will abandon them to reduce the rate of loss.

Thus, the extent to which interventions will reduce losses is of concern. Gao and colleagues [76] assumed that by increasing the proportion of combine harvesting, bulk transportation, mechanical drying, and depot storage in China to $100 \%$, the total losses in rice reaping, transportation, drying, and storage can be reduced from $6.9 \%$ to $2.6 \%$. Huang and colleagues [79] assumed that if the harvest loss rate of rice combine harvesting in China reaches $3 \%$, the total loss rate of rice reaping, threshing, winnowing, and field transportation can be reduced from $3.02 \%$ to $2.76 \%$, saving 540,000 tons of rice, 78,000 ha of land, and 26,000 tons of chemical fertilizer; if all the rice farmland is high standard type, the total loss rate can be further reduced to $2.08 \%$. However, interventions can have other effects besides reducing losses. Rosegrant and colleagues [19] found that increased infrastructure inputs are beneficial in reducing losses, improving social welfare, and have a 
positive economic rate of return, but the fall in agricultural prices owing to increased food supply can cause producers to experience a loss of benefits. The promotion of mechanical operations will replace labor [94] and thus may threaten the livelihood of farmers who previously depended on manual post-production operations. In Bangladesh, the increased use of mechanical rice milling means would lead to loss of jobs for women previously engaged in manual milling [16]. Ensuring that most participants benefit from mitigation strategies is a challenge to reducing food losses [2].

A cost-benefit analysis of interventions is necessary because any solution should not be more expensive than the lost food itself [54,59]. However, few such analyses have been conducted. Gummert and colleagues [49] argued that higher mechanization increases net income by $30-50 \%$. Hasan and colleagues [58] also indicated that using combine harvesters saves $57.61 \%$ costs compared to manual harvesting; however, combine harvesters need to harvest more than 35 hectares per year to be profitable. The 10-year savings from loss reduction due to the introduction of threshing machines in the Democratic Republic of Timor-Leste (approximately USD 33,200) were higher than the associated intervention costs of USD 14,000 [54].

\section{Conclusions}

Rice is the most essential cereal crop for consumption. More than 3 billion people rely on rice as a staple food [95]. Post-production losses reduce the available quantity of edible rice, causing a huge waste of resources and threatening the food security of farmers. This study reviews the existing research on losses during rice harvesting processes from the field to storage places, including the reaping, threshing, winnowing, and field transportation stages. We focused on the losses in terms of estimation methods, magnitudes of loss, causes of loss, impacts, and interventions.

The measurement of harvest losses is a complex issue. Currently, the main estimation methods are field trials and questionnaires. Field trials are time-consuming and labor-intensive but accurate, and can be designed to compare the losses of different rice varieties and operation methods; however, the estimates are different owing to differences in post-production operations. For example, reaping, threshing, and winnowing losses of combine harvesters cannot be calculated separately. Meanwhile, questionnaire surveys are easy to implement. Although their accuracy has been questioned, farmers' self-reports are still a good source of estimation in the absence of field data. Farmers' perceptions of losses are important because they influence the implementation of subsequent interventions. Only when farmers are aware of the severity of losses will they be willing to adopt mitigation measures.

The loss data from case studies are more effective than those on a global scale. It is difficult to describe rice harvest losses in one specific number because they vary by region, season, variety, post-harvest handling methods, and so on. Much more research has been done on quantitative loss than on qualitative loss. Overall, losses in the reaping and threshing stages were much greater than in winnowing and field transportation. Most of the loss data were presented as a percentage of production, with a few presented as absolute losses and values per unit area. When losses are estimated in percentage form, it should be clear whether the denominator is the actual or potential production or the amount obtained at a given stage, but this detail is not explained in some studies. There is no consistent conclusion as to whether the loss in mechanical operation is greater or less than that in manual operations, which may be related to the study site context. Overall, the loss rate was greater for high-yield rice than for local varieties and for large-scale farmers than for small-scale ones.

The general perception is that lack of knowledge, inadequate harvesting techniques, poor infrastructure, and inefficient harvest management practices are crucial causes of rice harvest losses. These losses not only result in less edible food and reduced income, but also have adverse impacts on the environment and resources. Many interventions have been proposed in the literature, such as improving infrastructure and increasing 
mechanization rates. However, few studies have conducted in-depth analysis on the effects and cost-benefit ratios of the interventions.

Increasing food supply by reducing losses can reduce the burden of increasing agricultural production, thus reducing the environmental and resource pressure on agricultural production and achieving sustainable development. The literature review helped to clarify the current research status and the direction of future reduction efforts. The review concluded that the magnitude and causes of rice harvest losses are well understood to some extent and that what is more important is the evaluation of the cost-benefit ratios, the effect of interventions, and whether the interventions will have other impacts besides loss reduction. For example, the reduction in prices owing to increased food supply may harm farmers' profits, and the promotion of machinery may lead to unemployment of farmers dependent on post-production manual work for their livelihood. Therefore, how should interventions be implemented if there is a trade-off between loss reduction and farmers welfare? These are much more important to examine after presenting interventions. In addition, only the harvesting loss was examined in this study; other stages of the supply chain are also critical to loss reduction, which will be left for future research.

Author Contributions: Conceptualization, X.Q. and D.K.; investigation, X.Q., D.K. and L.W.; data curation, X.Q.; software, X.Q.; writing-original draft preparation, X.Q.; writing-review and editing, D.K., L.W. and M.A.; funding acquisition, L.W. and M.A.; All authors have read and agreed to the published version of the manuscript.

Funding: This research was funded by the 2015 special scientific research project of grain public welfare industry_- "Investigation and evaluation of rice harvest loss" (IERHL, 201513004-2), by JSPS KAKENHI Grant Number JP19H03063, and by the scholarship from China Scholarship Council (CSC) under the Grant code-CSC201906350150.

Institutional Review Board Statement: Not applicable.

Informed Consent Statement: Not applicable.

Data Availability Statement: Not applicable.

Conflicts of Interest: The authors declare no conflict of interest. 
Appendix A

Table A1. Estimations of rice harvest loss.

\begin{tabular}{|c|c|c|c|c|}
\hline Method & Date & Region(s) & Magnitude & Citation(s) \\
\hline Field experiments & 2014-2015 & Nigeria & $\begin{array}{l}\text { Bag-beating: reaping }(1.56 \%) \text {, threshing }(2.27 \%) \text {, winnowing }(1.01 \%) \\
\text { Bambam: reaping }(1.77 \%) \text {, threshing }(4.15 \%) \text {, winnowing }(1.26 \%) \\
\text { Machinery: reaping }(1.90 \%) \text {, threshing }(5.96 \%) \text {, winnowing }(1.47 \%)\end{array}$ & [51] \\
\hline Field experiments, questionnaire & - & Nigeria & $\begin{array}{c}\text { Reaping: } 4.42 \% \text {, threshing and winnowing: } 4.97 \% \text {, transportation from field to home: } 0.34 \% \\
\text { Danbaba and colleagues [38] used the above estimation and the } 2016 \text { paddy production in Nigeria to calculate the } \\
\text { corresponding rice quantity and quality losses: } \\
\text { Reaping: } 0.78 \text { million metric tons; } 104.66 \text { billion naira } \\
\text { Threshing and winnowing: } 0.87 \text { million metric tons; } 117.42 \text { billion naira } \\
\text { Transportation from field to home: } 0.60 \text { million metric tons; } 8.03 \text { billion naira }\end{array}$ & {$[38,64]$} \\
\hline Questionnaire & 2014 & Nigeria & Reaping: $0.15 \mathrm{~kg}$ per farmer, threshing: $0.25 \mathrm{~kg}$ per farmer, winnowing: $0.15 \mathrm{~kg}$ per farmer & [37] \\
\hline Field experiments, questionnaire & & Ghana & 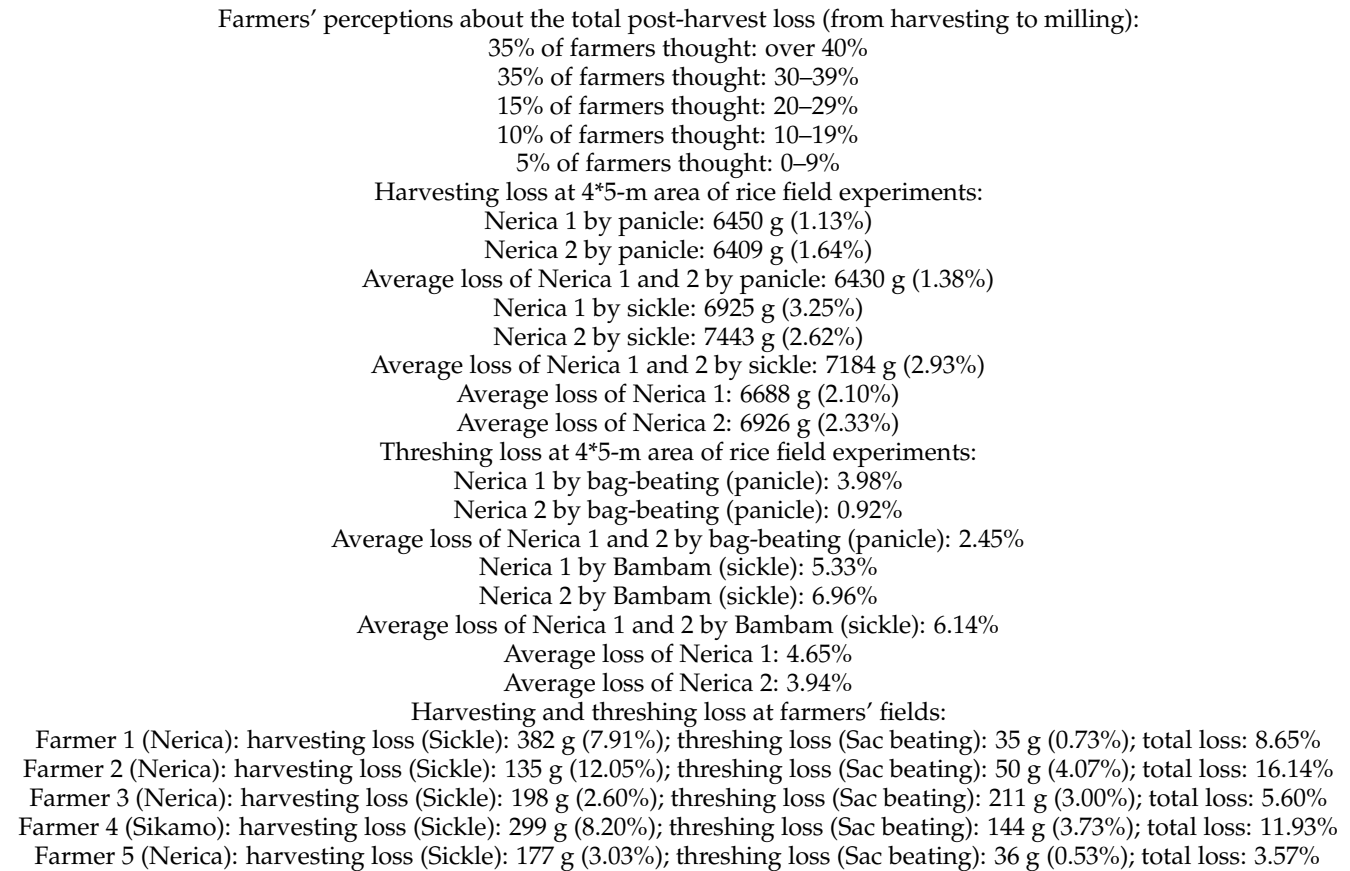 & {$[59,66]$} \\
\hline
\end{tabular}


Table A1. Cont.

\section{Method}

Date

Region(s)

Field experiments

Nobewam (Ghana)

Magnitude

Citation(s)

Qualitative threshing loss:

Variety 1: by Bambam (14.3\%), by drum (13.8\%); by sack $(12.8 \%)$

Variety 2: by Bambam (12.8\%); by drum (15.5\%); by sack $(10.0 \%)$

Average loss of variety 1 and 2: by Bambam (13.49\%); by drum (14.65\%); by sack (11.37\%)

Economic threshing loss $(\mathrm{GHC})$ :

Variety 1: by Bambam (81.2); by drum (78.7); by sack (72.6)
Variety 2: by Bambam (72.6); by drum (88.4); by sack (57.0)

Average loss of variety 1 and 2: by Bambam (76.86); by drum (83.51); by sack (64.79)

$$
\text { Shattering loss during reaping: } 2.8 \%
$$

Stacking loss after reaping and before threshing: $4.2 \%$

Manual threshing: unthreshed loss $(1.9 \% \pm 1.3 \%)$, scattered loss $(1.6 \% \pm 1.3 \%)$

Egypt

Manul reaping and tractor threshing: $2.49 \%$

$$
\text { Combine harvesting: } 1.35 \%
$$

Field experiments

2013

India

Reaping: $2.08 \% \pm 0.79 \%$, collection (including stacking, bundling and transportation up to th

arvest loss: $17.45 \mathrm{~kg}$

Mechanical threshing loss: $7.04 \mathrm{~kg} /$ acre; $0.31 \mathrm{~kg} /$ quintal; $0.31 \%$ of threshed amoun

Manual winnowing loss: $2.94 \mathrm{~kg} /$ acre; $0.13 \mathrm{~kg} /$ quintal; $0.13 \%$ of winnowed amount transported), trolley $(0.43 \mathrm{~kg} /$ quintal; $0.43 \%$ of amount transported), tempo $(0.15 \mathrm{~kg} /$ quintal; $0.15 \%$ of amount transported $)$

Harvest loss by farm size

$85 \mathrm{~kg} / q u i n t ;$ medium Average of four sizes: $0.78 \mathrm{~kg} /$ quin

Questionnaire 2010-2012 West Bengal (India)

Marginal size: $0.46 \mathrm{~kg} /$ quintal; small size: $0.34 \mathrm{~kg} /$ quintal; medium size: $0.28 \mathrm{~kg}$ /quintal; large size: $0.23 \mathrm{~kg} /$ quintal Average of four sizes: $0.32 \mathrm{~kg} /$ quintal

Winnowing loss by farm size:
Marginal size: $0.20 \mathrm{~kg} /$ quintal; small size: $0.15 \mathrm{~kg} /$ quintal; medium size: $0.12 \mathrm{~kg} /$ quintal; large size: $0.10 \mathrm{~kg} /$ quintal Average of four sizes: $0.13 \mathrm{~kg} /$ quinta Transportation loss by farm size:

Marginal size: $0.71 \mathrm{~kg} /$ quintal; small size: $0.61 \mathrm{~kg} /$ quintal; medium size: $0.52 \mathrm{~kg}$ /quintal; large size: $0.39 \mathrm{~kg} /$ quintal Average of four sizes: $0.55 \mathrm{~kg} /$ quintal 
Table A1. Cont.

Method Date

Region(s)

Questionnaire

2011-2012

Assam (India)

Magnitude

Citation(s)

Manual harvest loss (early season):

Local paddy: $10.83 \mathrm{~kg} /$ hectare; $0.25 \mathrm{~kg} /$ quintal; $0.25 \%$ of harvest amoun

HYV paddy: $15.89 \mathrm{~kg} /$ hectare; $0.59 \mathrm{~kg} /$ quintal; $0.59 \%$ of harvest amoun

Local paddy: $12.89 \mathrm{~kg} /$ hectare, $0.40 \mathrm{~kg} /$ quintal: $0.40 \%$ of harvest amoun

HYV paddy: $25.57 \mathrm{~kg} /$ hectare; $0.56 \mathrm{~kg} /$ quintal; $0.56 \%$ of harvest amount

Local paddy: $16.42 \mathrm{~kg} /$ hectare; $0.98 \mathrm{~kg} /$ quintal $: 0.98 \%$ :

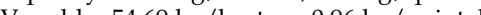

Th:

Local paddy: $0.45 \mathrm{~kg} /$ hectare $1.04 \mathrm{~kg} /$ quintal $104 \%$ of threshed

TYV paddy: $0.99 \mathrm{~kg} /$ hectare; $1.50 \mathrm{~kg} /$ quintal $1.50 \%$ of threshed amount

$$
\text { Winnowing loss (average of manual and mechanical): }
$$

Local paddy: $0.43 \mathrm{~kg} /$ hectare; $1.01 \mathrm{~kg} /$ quintal; $1.01 \%$ of threshed amount

Transportation loss from field to homestead: head load (1.38 kg/quintal; $1.38 \%$ of amount transported), bullock cart (0.00

$\mathrm{kg}$ /quintal; $0.00 \%$ of amount transported), trolley (1.85 kg/quintal; $1.85 \%$ of amount transported), tempo $(0.00 \mathrm{~kg} /$ quintal; $0.00 \%$ of amount transported), mini truck (1.90 kg/quintal; $1.90 \%$ of amount transported), hand cart (1.57 kg/quintal; $1.57 \%$ of

$$
\text { amount transported). Total (1.67 kg/quintal; } 1.67 \% \text { of amount transported) }
$$

$$
\text { Harvest loss by farm size: }
$$

Marginal size: $0.48 \mathrm{~kg} /$ quintal; small size: $0.58 \mathrm{~kg} /$ quintal; medium size: $0.62 \mathrm{~kg} /$ quintal; large size: $0.81 \mathrm{~kg} /$ quintal Average of four sizes: $0.62 \mathrm{~kg} /$ quintal

$$
\begin{aligned}
& \text { Threshing loss by farm size: } \\
& \text { The } 0.62 \mathrm{~kg} / \mathrm{qu} \text {. }
\end{aligned}
$$

Marginal size: $0.91 \mathrm{~kg} /$ quintal; small size: $0.98 \mathrm{~kg} /$ quintal; medium size: $1.41 \mathrm{~kg} /$ quintal; large size: $1.78 \mathrm{~kg} /$ quinta Average of four sizes: $1.27 \mathrm{~kg} /$ quinta Winnowing loss by farm size:

Marginal size: $0.79 \mathrm{~kg} /$ quintal; small size: $0.88 \mathrm{~kg}$ /quintal; medium size: $1.02 \mathrm{~kg} /$ quintal; large size: $1.22 \mathrm{~kg} /$ quinta Average of four sizes: $0.98 \mathrm{~kg} /$ quinta

Marginal size: $1.30 \mathrm{~kg} /$ quintal; small size: $1.49 \mathrm{~kg} /$ quintal; medium size: $1.79 \mathrm{~kg} /$ quintal; large size: $2.11 \mathrm{~kg} /$ quintal Average of four sizes: $1.67 \mathrm{~kg} /$ quintal 
Table A1. Cont.

\section{Method}

Date

Questionnaire

2011-2012

Karnataka (India)

Region(s)

\section{Magnitude}

Harvest loss (including combine harvester and manual harvesting):

arly season: $33.2 \mathrm{~kg} /$ acre; $1.74 \mathrm{~kg}$ /quintal; $1.74 \%$ of harvest amount

Mid-season: $37.4 \mathrm{~kg} /$ acre; $1.92 \mathrm{~kg}$ /quintal; $1.92 \%$ of harvest amoun

Late-season: $41.4 \mathrm{~kg} /$ acre; $1.86 \mathrm{~kg}$ /quintal; $1.86 \%$ of harvest amoun

Total: $37.1 \mathrm{~kg} / \mathrm{acre} ; 1.90 \mathrm{~kg} /$ quintal; $1.90 \%$ of harvest amoun

Manual threshing loss: $21.92 \mathrm{~kg} / \mathrm{acre} ; 1.24 \mathrm{~kg} /$ quintal

Mechanical threshing loss: $25.37 \mathrm{~kg} / \mathrm{acre} ; 1.16 \mathrm{~kg}$ /quintal

Manual winnowing loss: $20.21 \mathrm{~kg} /$ acre; $1.14 \%$ of winnowed amount

Mechanical winnowing loss: $8.33 \mathrm{~kg} / \mathrm{acre} ; 0.46 \%$ of winnowed amount
Transportation loss (from field to homestead or market): head load (0.38 kg/quintal; $0.38 \%$ of amount transported), bullock cart

$(0.62 \mathrm{~kg} /$ quintal $0.62 \%$ of amount transported), trolley $(0.64 \mathrm{~kg} /$ quintal; $0.64 \%$ of amount transported $)$, truck $(0.80 \mathrm{~kg} /$ quintal

$0.80 \%$ of amount transported). Total ( $0.64 \mathrm{~kg} /$ quintal; $0.64 \%$ of amount transported) Harvest loss by farm size:

/quize: $1.26 \mathrm{~kg} /$ quintal Average of four sizes: $1.90 \mathrm{~kg} /$ quint

Marginal size: $0.48 \mathrm{~kg} /$ quintal; small size: $0.17 \mathrm{~kg} /$ quintal; medium size: $0.11 \mathrm{~kg} /$ quintal; large size: $0.00 \mathrm{~kg} /$ quintal Average of four sizes: $0.20 \mathrm{~kg} /$ quintal
Winnowing loss by farm size:

$\begin{aligned} & \text { Winnowing loss by farm size: } \\ & \text { Marginal size: } 0.16 \mathrm{~kg} / \text { quintal; small size: } 0.12 \mathrm{~kg} / \text { quintal; medium size: } 0.04 \mathrm{~kg} / \text { quintal; large size: } 0.00 \mathrm{~kg} / \text { quintal }\end{aligned}$ Average of four sizes: $0.08 \mathrm{~kg} /$ quintal

Transportation loss by farm size:
Marginal size: $0.84 \mathrm{~kg} /$ quintal; small size: $0.39 \mathrm{~kg} /$ quintal; medium size: $0.55 \mathrm{~kg} /$ quintal; large size: $0.52 \mathrm{~kg} /$ quintal Average of four sizes: $0.57 \mathrm{~kg} /$ quintal Mechanical harvest loss (HYV paddy):

Early stage: $93.70 \mathrm{~kg} / \mathrm{acre} ; 3.40 \mathrm{~kg} /$ quintal; $3.40 \%$ of harvested amount
Mid-season: $38.30 \mathrm{~kg} /$ acre; $1.40 \mathrm{~kg} /$ quintal; $1.40 \%$ of harvested amount

Transportation loss by tractor-trolley (to the market): $0.063 \mathrm{~kg} /$ quintal; $0.0002 \%$ of amount transported$$
\text { Harvest loss by far } \mathrm{kg} / \mathrm{qui}
$$

Marginal size: $1.19 \mathrm{~kg} /$ quintal; small size: $1.66 \mathrm{~kg}$ /quintal; medium size: $1.64 \mathrm{~kg} /$ quintal; large size: $1.52 \mathrm{~kg} /$ quintal Average of four sizes: $1.54 \mathrm{~kg} /$ quintal

$\begin{aligned} & \text { Transportation loss by farm size: } \\ & \text { Marginal size: } 0.09 \mathrm{~kg} / \text { quintal; small size: } 0.09 \mathrm{~kg} / \text { quintal; medium size: } 0.05 \mathrm{~kg} / \text { quintal; large size: } 0.06 \mathrm{~kg} / \text { quintal }\end{aligned}$ 
Table A1. Cont.

Tiruvarur district:
Harvest loss of HYV paddy (including mechanical (over 90\%) and manual harvesting)

Early season: $92.32 \mathrm{~kg} /$ acre; $3.87 \mathrm{~kg} /$ quintal; $3.87 \%$ of harvest amount

Mid-season: $51.2 \mathrm{~kg} /$ acre; $2.21 \mathrm{~kg} /$ quintal; $2.21 \%$ of harvest amount

Threshing loss of HYV paddy (including mechanical and manual threshing): $2.11 \mathrm{~kg} /$ quintal

Winnowing loss of HYV paddy (including mechanical and manual threshing): $0.18 \mathrm{~kg} /$ quinta Transportation loss by tempo (to the market): $0.56 \mathrm{~kg} /$ quintal

$$
\text { Villupuram district: }
$$

Early season (mechanical harvesting): $71.75 \mathrm{~kg} /$ acre; $2.96 \mathrm{~kg} /$ quintal; $2.96 \%$ of harvest amount Mid-season (mostly mechanical harvesting): $69.79 \mathrm{~kg} /$ acre; $2.87 \mathrm{~kg} /$ quintal; $2.87 \%$ of harvest amount

Late-season (mechanical harvesting): $89.3 \mathrm{~kg} / \mathrm{acre} ; 3.60 \mathrm{~kg} /$ quintal; $3.60 \%$ of harvest amoun

Threshing loss of HYV paddy (including mechanical and manual threshing): $0.83 \mathrm{~kg} /$ quintal Transportation loss by tempo (to the market): $0.65 \mathrm{~kg} /$ quintal

$$
\text { Harvest loss by farm size: }
$$

Questionnaire 2010-2012 Tamil Nadu (India)

Tiruvarur district: marginal size: $3.12 \mathrm{~kg} /$ quintal; small size: 3 farm size:

quintal; small size: $3.08 \mathrm{~kg}$ /quintal; medium size: $3.14 \mathrm{~kg} /$ quintal; large size: 3.07

$\mathrm{kg} /$ quintal; average of four sizes: $3.10 \mathrm{~kg} /$ quintal

kg/quintal; small size: $3.19 \mathrm{~kg} /$ quintal; medium size: $2.94 \mathrm{~kg} /$ quintal; large size: 3.16

$\mathrm{kg} /$ quintal; average of four sizes: $3.16 \mathrm{~kg} /$ quintal

Average of two districts: $3.13 \%$

Tiruvarur district: marginal size: $1.73 \mathrm{~kg}$ /quintal; small size: $1.57 \mathrm{~kg} /$ quintal; medium size: $2.77 \mathrm{~kg}$ /quintal; large size: 1.38 $\mathrm{kg} /$ quintal; average of four sizes: $2.11 \mathrm{~kg} /$ quintal

Villupuram district: marginal size: $1.12 \mathrm{~kg} /$ quintal; small size: $1.07 \mathrm{~kg} /$ quintal; medium size: $0.46 \mathrm{~kg}$ /quintal; large size: 0.83 $\mathrm{kg} /$ quintal; average of four sizes: $0.83 \mathrm{~kg} /$ quintal

Average of two districts: $1.47 \%$
Winnowing loss by farm size:

Tiruvarur district: marginal size: $0.15 \mathrm{~kg}$ /quintal; medium size: $0.46 \mathrm{~kg} /$ quintal; large size: $0.10 \mathrm{~kg} /$ quintal; average of four sizes: $0.18 \mathrm{~kg} /$ quintal

Tiruvarur district: marginal size: $0.73 \mathrm{~kg} /$ quintal; small size: $0.56 \mathrm{~kg} /$ quintal; medium size: $0.50 \mathrm{~kg} /$ quintal; large size: 0.44

$\mathrm{kg} /$ quintal; average of four sizes:0.56 kg/quintal
Villupuram district: marginal size: $0.84 \mathrm{~kg} /$ quintal; small size: $0.54 \mathrm{~kg} /$ quintal; medium size: $0.40 \mathrm{~kg}$ /quintal; large size: 0.65 $\mathrm{kg} /$ quintal; average of four sizes: $0.65 \mathrm{~kg} /$ quintal 
Table A1. Cont.

Method Date

Region(s)

Questionnaire

2011-2012

Uttar Pradesh (India)

Magnitude

Citation(s)

Harvest loss of HYV paddy (including mechanical and manual harvesting):

Early season: $40.65 \mathrm{~kg} / \mathrm{acre} ; 0.92 \mathrm{~kg} /$ quintal; $0.92 \%$ of harvest amount

Mid-season: $55.81 \mathrm{~kg} / \mathrm{acre} ; 3.69 \mathrm{~kg} /$ quintal; $3.69 \%$ of harvest amount

Late-season: $36.36 \mathrm{~kg} /$ acre; $1.43 \mathrm{~kg} /$ quintal; $1.43 \%$ of harvest amount

Winnowing loss of HYV paddy: $2.71 \mathrm{~kg} / \mathrm{acre}, 1.28 \mathrm{~kg} /$ quintal, $1.28 \%$ of winnowed amount

Transportation loss: head load ( $0.14 \mathrm{~kg} /$ quintal; $0.14 \%$ of amount transported), bullock cart (1.70 kg/quintal; $0.88 \%$ of amoun transported), trolley $(0.51 \mathrm{~kg} /$ quintal; $0.51 \%$ of amount transported), tempo $(0.72 \mathrm{~kg} /$ quintal; $0.72 \%$ of amount transported $)$. Total $(0.49 \mathrm{~kg} /$ quintal; $0.49 \%$ of amount transported)

Marginal size: $2.53 \mathrm{~kg}$ /quintal; small size: $3.19 \mathrm{~kg} /$ quintal; medium size: $1.56 \mathrm{~kg} /$ quintal; large size: $2.45 \mathrm{~kg} /$ quintal Average of four sizes: $2.71 \mathrm{~kg} /$ quintal

Marginal size: $1.78 \mathrm{~kg} /$ quintal; small size: $1.23 \mathrm{~kg} /$ quintal; medium size: $0.58 \mathrm{~kg} /$ quintal; large size: $0.98 \mathrm{~kg} /$ quintal Average of four sizes: $1.28 \mathrm{~kg} /$ quintal

Winnowing loss by farm size:
Wing

Marginal size: $0.64 \mathrm{~kg} /$ quintal; small size: $0.41 \mathrm{~kg} /$ quintal; medium size: $0.10 \mathrm{~kg} /$ quintal; large size: $0.16 \mathrm{~kg} /$ quintal Average of four sizes: $0.40 \mathrm{~kg} /$ quinta

Transportation loss by farm size:
Marginal size: $0.49 \mathrm{~kg} /$ quintal; small size: $0.62 \mathrm{~kg} /$ quintal; medium size: $0.41 \mathrm{~kg} /$ quintal; large size: $0.31 \mathrm{~kg} /$ quintal Average of four sizes: $0.48 \mathrm{~kg} /$ quintal

\begin{tabular}{|c|c|c|c|c|}
\hline Questionnaire & 2003-2004 & Karnataka (India) & $\begin{array}{c}\text { Harvesting loss: } 0.40 \mathrm{~kg} / \text { quintal, threshing loss: } 0.52 \mathrm{~kg} / \text { quintal, cleaning/winnowing loss: } 0.20 \mathrm{~kg} \text { /quintal, transportation } \\
\text { loss: } 0.50 \mathrm{~kg} / \text { quintal }\end{array}$ & [74] \\
\hline Field experiments & 2010 & Karnataka (India) & Combine harvester: $2.88 \%-3.60 \%$ & [75] \\
\hline Literature review & 2010 & China & $\begin{array}{c}\text { Combine harvesting: } 1.5 \% \\
\text { Segmented harvesting: } 4.4 \% \\
\text { Harvesting loss (average of combine harvesting and segmented harvesting): } 2.7 \% \\
\text { Package transportation loss (from field to homestead or storage): } 1 \% \\
\text { Bulk transportation loss (from field to homestead or storage): } 0.3 \% \\
\text { Transportation loss (average of package transportation and bulk transportation): } 0.9 \%\end{array}$ & [76] \\
\hline
\end{tabular}


Table A1. Cont.

Method Date

Region(s)

Questionnaire 2014

China

\section{Magnitude}

Citation(s)

, to packaging) in nationwide

$26.93 \%$ of farmers thought: less than $3 \%$

$29.20 \%$ of farmers thought: $3-4 \%$

$18.30 \%$ of farmers thought: $4-5 \%$

$13.07 \%$ of farmers thought: $5-6 \%$

$5.68 \%$ of farmers thought: $6-7 \%$

$6.82 \%$ of farmers thought: over $7 \%$

Farmers' perceptions about harvest loss (from cutting, threshing, to packaging) in east region $26.38 \%$ of farmers thought: less than $3 \%$

$23.77 \%$ of farmers thought: $3-4 \%$

$18.55 \%$ of farmers thought: $4-5 \%$

$12.75 \%$ of farmers thought: $5-6 \%$

$12.17 \%$ of farmers thought: over $7 \%$

Farmers' perceptions about harvest loss (from cutting, threshing, to packaging) in central region:

$24.39 \%$ of farmers thought: less than $3 \%$

$32.52 \%$ of farmers thought: $3-4 \%$

$13.82 \%$ of farmers thought: $4-5 \%$

$16.67 \%$ of farmers thought: $5-6 \%$

$8.13 \%$ of farmers thought: $6-7 \%$

Farmers' perceptions about harvest loss (from cutting, threshing, to packaging) in west region:

$19.28 \%$ of farmers thought: less than $3 \%$

$35.43 \%$ of farmers thought: $3-4 \%$

$26.46 \%$ of farmers thought: $4-5 \%$

$13.00 \%$ of farmers thought: $5-6 \%$

$3.59 \%$ of farmers thought: $6-7 \%$

$2.24 \%$ of farmers thought: over $7 \%$

(from cutting, threshing, to packaging) in northeast:

$65.15 \%$ of farmers thought: less than $3 \%$

$22.72 \%$ of farmers thought: $3-4 \%$

$6.06 \%$ of farmers thought: $4-5 \%$

$1.52 \%$ of farmers thought: $5-6 \%$

$1.52 \%$ of farmers thought: $6-7 \%$

$3.03 \%$ of farmers thought: over $7 \%$

Sickle reaping: scattered loss $(0.09 \%)$, stacking loss $(0.21 \%)$, uncut loss $(0.11 \%)$

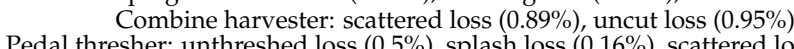

Pedal thresher: unthreshed loss $(0.5 \%)$, splash loss $(0.16 \%)$, scattered loss $(0.16 \%)$

Field experiments

Zhejiang (China)

Electronical thresher: unthreshed loss $(0.6 \%)$, splash loss $(0.26 \%)$, scattered loss $(0.59 \%)$ 
Table A1. Cont.

\section{Method}

Region(s)

Magnitude

Citation(s)

Harvest loss in field experiments:

Loss by Kubota, $25 \%$ moisture content, $0.25 \mathrm{~m}$ stubble height, $11-12 \mathrm{~km} / \mathrm{h}$ harvest speed: $545.87 \pm 5.26 \mathrm{~kg} / \mathrm{hm}^{2}$ Loss by Kubota, $25 \%$ moisture content, $0.25 \mathrm{~m}$ stubble height, $8-9 \mathrm{~km} / \mathrm{h}$ harvest speed: $436.43 \pm 17.75 \mathrm{~kg} / \mathrm{hm}^{2}$ Loss by Kubota, $25 \%$ moisture content, $0.25 \mathrm{~m}$ stubble height, $5-6 \mathrm{~km} / \mathrm{h}$ harvest speed: $171.46 \pm 1.62 \mathrm{~kg} / \mathrm{hm}^{2}$ Loss by Kubota, $21 \%$ moisture content, $0.17 \mathrm{~m}$ tubble height, 11-12 km/h harest speed: $108.7 \pm 3.36 \mathrm{~kg} / \mathrm{hm}^{2}$ Loss by Kon

Loss by Kubota, $21 \%$ moisture content, $0.17 \mathrm{~m}$ stubble height, $8-9 \mathrm{~km} / \mathrm{h}$ harvest speed: $46.8 \pm 1.98 \mathrm{~kg} / \mathrm{hm}^{2}$

Field experiments, questionnaire

2019

Heilongjiang (China)

Loss by Yanmar, 25\% moisture content, $0.25 \mathrm{~m}$ stubble height, $11-12 \mathrm{~km} / \mathrm{h}$ harvest speed: $530.67 \pm 7.12 \mathrm{~kg} / \mathrm{hm}^{2}$

Loss by Yanmar, 25\% moisture content, $0.25 \mathrm{~m}$ stubble height, $8-9 \mathrm{~km} / \mathrm{h}$ harvest speed: $447.07 \pm 7.49 \mathrm{~kg} / \mathrm{hm}$

Loss by Yanmar, $25 \%$ moisture content, $0.25 \mathrm{~m}$ stubble height, $5-6 \mathrm{~km} / \mathrm{h}$ harvest speed: $253.87 \pm 2.73 \mathrm{~kg} / \mathrm{hm}^{2}$

Loss by Yanmar, 21\% moisture content, $0.17 \mathrm{~m}$ stubble height, $11-12 \mathrm{~km} / \mathrm{h}$ harvest speed: $211.37 \pm 11.3 \mathrm{~kg} / \mathrm{hm}^{2}$

Loss by Yanmar, 21\% moisture content, $0.17 \mathrm{~m}$ stubble height, $8-9 \mathrm{~km} / \mathrm{h}$ harvest speed: $80.40 \pm 17.75 \mathrm{~kg} / \mathrm{hm}^{2}$

Loss by Yanmar, 21\% moisture content, $0.17 \mathrm{~m}$ stubble height, $5-6 \mathrm{~km} / \mathrm{h}$ harvest speed: $46.43 \pm 1.62 \mathrm{~kg} / \mathrm{hm}^{2}$

$$
\text { Harvest loss by farmers' perception: } 3-5 \%
$$

Harvest loss (including reaping loss, threshing loss, winnowing loss, and transportation loss from field to homestead)

Combine harvester: The Northeast Plain (3.02\%), Yangtze River basin (3.17\%), Southeast Coast (4.12\%). Average nationwide

Field experiment

2016

2016

979-1980
Chin

$$
(3.44 \%)
$$

$$
(1.66 \%)
$$$$
\text { Harvest loss nationwide: } 3.02 \%
$$

Segmented harvesting: reaping loss $(2.48 \%)$, threshing loss $(0.76 \%)$, winnowing loss $(0.42 \%)$, transportation loss $(0.22 \%)$ Combine harvesting: loss from reaping to winnowing $(3.27 \%)$, transportation $(0.12 \%)$ Average nationwide harvest loss: $3.65 \%$

\section{Harvest loss (from reaping to field transportation):}

$$
\text { Small-scale farmer: } 4.59 \%
$$

Large-scale farmer: $2.60 \%$

$$
\text { Threshing loss: }
$$

Field experiments $\quad$ 1979-1980 $\quad$ Bangladesh

By bullock treading: $2.54 \%$ 
Table A1. Cont.

\section{Method}

Region(s)

Magnitude

Citation(s)

\section{Mymensingh region:}

Harvesting loss: Aman season (2.45\%), Boro season (2.47\%); Aus season (3.00\%)

Threshing loss: Aman season (1.80\%), Boro season (2.23\%); Aus season (2.96\%)

Transportation loss: Aman season (1.59\%), Boro season (2.01\%); Aus season (1.64\%) Khulna region:

Harvesting loss: Aman season (1.54\%), Boro season (1.40\%); Aus season (0.21\%)

Threshing loss: Aman season (0.62\%), Boro season ( $0.83 \%)$; Aus season (1.50\%)

Transportation loss: Aman season (0.69\%), Boro season (1.03\%); Aus season $(0.25 \%)$

Harvesting loss: Aman season (1.51\%), Boro season (1.78\%); Aus season (2.06\%)

Questionnaire Bangladesh

Threshing los: Ams season (1.11\%), Boro season (1.28\%); Aus season ( $0.45 \%)$

Comilla region:

Harvesting loss: Aman season (1.07\%), Boro season (1.02\%), Aus season (0.89\%)

Threshing loss: Aman season (0.73\%), Boro season ( $0.74 \%)$; Aus season $(0.71 \%)$

Transportation loss: Aman season (0.63\%), Boro season (0.71\%); Aus season (0.54\%)
Nationwide:

Harvesting loss: Aman season (1.60\%), Boro season (1.62\%); Aus season (1.91\%)
Threshing loss: Aman season (0.87\%), Boro season (1.13\%); Aus season (1.07\%)

Transportation loss: Aman season (1.10\%), Boro season (1.22\%); Aus season (1.79\%)

Field experiment

Field experiments

2013

2018 Rangpur
(Bangladesh)

Bangladesh Harvesting loss (shattering loss): reaping: $1.40 \%$

BR26: Reaping loss by sickle (2.1\%); Field transportation loss by trolley $(0.2 \%)$, by head carry $(0.65 \%)$, by shoulder carry $(0.75 \%)$;

threshing loss by ODT $(1.21 \%)$, by CDT $(1.98 \%)$; winnowing loss by Kula $(0.25 \%)$, by winnower $(0.25 \%)$
BRRI dhan27: Reaping loss by sickle (2.15\%); Field transportation loss by trolley $(0.195 \%)$, by head carry $(0.84 \%)$, by shoulder carry $(0.79 \%)$; threshing loss by ODT $(1.1 \%)$, by CDT $(1.2 \%)$; winnowing loss by Kula $(0.17 \%)$, by winnower $(0.26 \%)$

BR23. Reaping loss by sickle (1.88\%); Field transportation season:

.

BR11: Reaping loss by sickle ( $2 \%$ ) Field transportation loss by trolley $(0.23 \%)$, by head carry $(0.66 \%)$, by shoulder carry $(0.63 \%)$ threshing loss by ODT $(0.86 \%)$, by CDT (2.26\%); winnowing loss by Kula $(0.21 \%)$, by winnower $(0.29 \%)$
to

Field experiments 2008-2010 Bangladesh

BRRI dhan28: Reaping loss by sickle (1.83\%); Field transportation loss by trolley $(0.15 \%)$, by head carry $(0.51 \%)$, by shoulder carry $(0.72 \%)$; threshing loss by ODT $(1.1 \%)$, by CDT $(2.14 \%)$; winnowing loss by Kula $(0.17 \%)$, by winnower $(0.28 \%)$ BRRI dhan29: Reaping loss by sickle (1.94\%); Field transportation loss by trolley $(0.24 \%)$, by head carry $(0.81 \%)$, by shoulder carry $(0.72 \%)$; threshing loss by ODT $(1.13 \%)$, by CDT $(1.96 \%)$; winnowing loss by Kula $(0.18 \%)$, by winnower $(0.16 \%)$ Cutting loss: Aus season (2.13\%); Aman season (1.94\%); Boro season (1.89\%)

Field stacking g loss: Aus season (0.69\%); Aman season (0.97\%); Boro season $(0.83 \%)$

Field transportation loss: Aus season (0.57\%); Aman season ( $0.48 \%)$; Boro season $(0.53 \%)$ Threshing loss: Aus season (3.09\%); Aman season (3.23\%); Boro season $(3.16 \%)$
Threshing loss: Aus season (0.47\%); Aman season (0.48\%); Boro season $(0.39 \%)$ 
Table A1. Cont.

\begin{tabular}{|c|c|c|c|c|}
\hline Method & Date & Region(s) & Magnitude & Citation(s) \\
\hline Questionnaire & 2009-2010 & Bangladesh & $\begin{array}{l}\text { Reaping loss: Aman season (1.95 kg/quintal); Boro season (1.66 kg/quintal) } \\
\text { Threshing loss: Aman season (0.64 kg/quintal); Boro season (0.56 kg/quintal) } \\
\text { Winnowing loss: Aman season (0.32 kg/quintal); Boro season (0.24 kg/quintal) }\end{array}$ & [82] \\
\hline Field experiments & 2010 & Iran & $\begin{array}{c}\text { Quantitative loss: } \\
\text { Reaping loss: T1 }(1.60 \%) ; \mathrm{T} 2(1.48 \%) ; \mathrm{T} 3(1.54 \%) \\
\text { Threshing loss: T1 }(0.98 \%) ; \mathrm{T} 2(1.04 \%) ; \mathrm{T} 3(1.12 \%) \\
\text { Reaping + threshing loss: T1 }(2.58 \%) ; \mathrm{T} 2(2.52 \%) ; \mathrm{T} 3(2.26 \%) ; \mathrm{T} 4(2.27 \%) ; \mathrm{T} 5(2.4 \%) \\
\text { Qualitative loss: } \\
\text { T1 (2.05\%); T2 (2.44\%); T3 (2.41\%); T4 (0.47\%); T5 }(0.75 \%) \\
\text { The average quantitative loss of T1-T3: } 2.58 \% ; \text { The average quantitative loss of T4-T5: } 2.33 \% . \\
\text { The average qualitative loss of T1-T3: } 2.30 \% \text {; The average qualitative loss of T4-T5: } 0.61 \% \text {. } \\
\text { Quantitative losses are the result of shattering and losing of grain and non-threshed panicles during reaping and threshing. } \\
\text { Qualitative losses are owing to broken, husked, and cracked grains from environmental and mechanical impacts. } \\
\text { T1-T3 are regarded as indirect harvesting, T4-T5 are regarded as direct harvesting. } \\
\text { Note: T1: Manual harvesting (cutting with sickle) + tractor-driven thresher. } \\
\text { T2: Rice reaper + tractor-driven thresher. } \\
\text { T3: Rice reaper + threshing by a universal combine equipped with pick-up header. } \\
\text { T4: Head-feed rice combine harvester. } \\
\text { T5: Whole-crop rice combine harvester. }\end{array}$ & [50] \\
\hline Field experiments & 2014-2015 & Myanmar & $\begin{array}{c}\text { Wet season 2014: } \\
\text { Harvesting loss: IPR (16.0\%); FP1W (28.2\%); FP4W (23.63\%) } \\
\text { Manual cutting and handing loss: IPR (13.6\%); FP1W (20.8\%); FP4W (14.4\%) } \\
\text { In-field stacking loss: FP1W (0.3\%); FP4W (0.6\%) } \\
\text { Threshing loss: IPR (2.4\%); FP1W (7.2\%); FP4W (8.7\%) } \\
\text { Dry season 2015: } \\
\text { Harvesting loss: IPRc (1.7\%); FP (9.3\%) } \\
\text { Manual cutting and handing loss: FP (6.7\%) } \\
\text { Threshing loss: FP (2.6\%) } \\
\text { Combine harvesting loss: IPRc (1.7\%) } \\
\text { Dry season 2016: } \\
\text { Harvesting loss: IPRc (0.9\%); FP (4.0\%) } \\
\text { Manual cutting and handing loss: FP (1.8\%) } \\
\text { Threshing loss: FP (2.2\%) } \\
\text { Combine harvesting loss: IPRc (0.9\%) } \\
\text { Note: IPR: manual cutting, threshing immediately after cutting using improved thresher } \\
\text { FP1W: manual cutting, stacking 1 week in field, less developed thresher } \\
\text { FP4W: manual cutting, stacking 4 weeks in field, less developed thresher } \\
\text { IPRc: combine harvester } \\
\text { FP: manual cutting, threshing immediately after cutting using less improved thresher }\end{array}$ & [49] \\
\hline Field experiments & 1981 & Indonesia & $\begin{array}{l}\text { Traditional ani-ani method: shattered and dropped losses }(1.40 \%) \text {; uncut losses }(4.48 \%) \text {; foot-treading threshing losses }(2.38 \%) \\
\text { Sickle method: shattered and dropped losses }(1.28 \%) \text {; uncut losses }(1.92 \%) \text {; beating threshing losses }(5.63 \%)\end{array}$ & [83] \\
\hline $\begin{array}{l}\text { Questionnaire, direct } \\
\text { observation, focus group } \\
\text { discussion }\end{array}$ & 2015 & $\begin{array}{l}\text { Democratic Republic } \\
\text { of Timor-Leste }\end{array}$ & $\begin{array}{l}\text { Manual harvesting loss: } 3.5 \% \text { in harvesting stage; } 3.5 \% \text { of the initial quantity; USD } 3140 \\
\text { Transportation loss from field to homestead: } 1.5 \% \text { in the transportation stage; } 1.45 \% \text { of the initial quantity; USD } 1300 \\
\text { Thresher machine loss: } 5 \% \text { in the threshing stage; } 4.75 \% \text { of the initial quantity; USD } 4260 \\
\text { Manual winnowing: } 0.5 \% \text { in the winnowing stage; } 0.45 \% \text { of the initial quantity; USD } 400\end{array}$ & [54] \\
\hline
\end{tabular}


Table A1. Cont.

\section{Method}

Date

Region(s)

Field experiments

1979

Dominican Republic
Magnitude

Citation(s)

Harvest loss by region:

Central-Northeast: $17.41 \%$

Northwest: $21.58 \%$

Harvest by size (tarea):

$1-50: 18.24 \%$

101+: $12.27 \%$

Harvest loss by harvest method:

Manual: $20.32 \%$

Harvest loss by hand-threshing method:

Stick: $19.52 \%$

Platform: $22.01 \%$

Sickle reaping loss in Indonesia: wet season $(0.7 \%)$, dry season $(0.5 \%)$

Average loss as a percentage of estimated potential yield:

Traditional hand cutting loss: Thailand (9.3\%); Myanmar (1.9\%)

Shoulder power reaper: Thailand (5.2\%); Myanmar (5.4\%)

Reaper-binder: Thailand (5.2\%); Myanmar (5.2\%)

Combine harvester: Thailand (1.1\%); Myanmar (2.1\%)

Field stacking and bundling: Bangladesh $(0.6 \%)$; Myanmar $(0.5 \%)$

Loss in China (Zhejiang) in 1987/1989 (Average loss as a percentage of production)

Threshing. by pedal thresher $(0.80 \%)$, by motor thresher $(1.52 \%)$. Average loss $(1.31 \%)$ 


\section{References}

1. Food and Agriculture Organization of the United Nations. How to Feed the World in 2050. Available online: http://www.fao. org/fileadmin/templates/wsfs/docs/expert_paper/How_to_Feed_the_World_in_2050.pdf (accessed on 15 June 2021).

2. Shafiee-Jood, M.; Cai, X. Reducing Food Loss and Waste to Enhance Food Security and Environmental Sustainability. Environ. Sci. Technol. 2016, 50, 8432-8443. [CrossRef] [PubMed]

3. Chen, X.; Cui, Z.; Fan, M.; Vitousek, P.; Zhao, M.; Ma, W.; Wang, Z.; Zhang, W.; Yan, X.; Yang, J.; et al. Producing More Grain with Lower Environmental Costs. Nature 2014, 514, 486-489. [CrossRef] [PubMed]

4. Hodges, R.J.; Buzby, J.C.; Ben Nett, A.N.D.B. Postharvest Losses and Waste in Developed and Less Developed Countries: Opportunities to Improve Resource Use. J. Agric. Sci. 2010, 149, 37-45. [CrossRef]

5. Irfanoglu, Z.B.; Baldos, U.; Hertel, T.; van der Mensbrugghe, D. Impacts of Reducing Global Food Loss and Waste on Food Security, Trade, GHG Emissions and Land Use. In Proceedings of the 17th Annual Conference on Global Economic Analysis, Dakar, Senegal, 18-20 June 2014; pp. 1-8.

6. Kummu, M.; de Moel, H.; Porkka, M.; Siebert, S.; Varis, O.; Ward, P.J. Lost Food, Wasted Resources: Global Food Supply Chain Losses and Their Impacts on Freshwater, Cropland, and Fertiliser Use. Sci. Total Environ. 2012, 438, 477-489. [CrossRef]

7. Zorya, S.; Morgan, N.; Diaz Rios, L. Missing Food: The Case of Postharvest Grain Losses in Sub-Saharan Africa; The World Bank: Washington, DC, USA, 2011.

8. Foley, J.A.; Ramankutty, N.; Brauman, K.A.; Cassidy, E.S.; Gerber, J.S.; Johnston, M.; Mueller, N.D.; O'Connell, C.; Ray, D.K.; West, P.C.; et al. Solutions for a Cultivated Planet. Nature 2011, 478, 337-342. [CrossRef]

9. Bai, Z.G.; Dent, D.L. Global Assessment of Land Degradation and Improvement: Pilot Study in Kenya; ISRIC: Wageningen, The Netherlands, 2006.

10. Jalava, M.; Guillaume, J.H.A.; Kummu, M.; Porkka, M.; Siebert, S.; Varis, O. Diet Change and Food Loss Reduction: What Is Their Combined Impact on Global Water Use and Scarcity? Earth's Future 2016, 4, 62-78. [CrossRef]

11. Yu, Y.; Jaenicke, E.C. Estimating Food Waste as Household Production Inefficiency. Am. J. Agric. Econ. 2020, 102, 525-547. [CrossRef]

12. Sun, S.K.; Lu, Y.J.; Gao, H.; Jiang, T.T.; Du, X.Y.; Shen, T.X.; Wu, P.T.; Wang, Y.B. Impacts of Food Wastage on Water Resources and Environment in China. J. Clean. Prod. 2018, 185, 732-739. [CrossRef]

13. Liu, J.; Lundqvist, J.; Weinberg, J.; Gustafsson, J. Food Losses and Waste in China and Their Implication for Water and Land. Environ. Sci. Technol. 2013, 47, 10137-10144. [CrossRef]

14. Food and Agriculture Organization of the United Nations. Food Wastage Footprint: Impacts on Natural Resources-Summary Report; Food and Agriculture Organization of the United Nations: Rome, Italy, 2013.

15. Food and Agriculture Organization of the United Nations. Food Loss Prevention in Perishable Crops; Food and Agriculture Organization of the United Nations: Rome, Italy, 1981; ISBN 92-5-101028-5.

16. Greeley, M. Postharvest Technologies: Implications for Food Policy Analysis; World Bank: Washington, DC, USA, 1991.

17. United Nations Sustainable Development Goals. Goal 12.3. Available online: https://www.unep.org/thinkeatsave/about/sdg123-food-waste-index (accessed on 17 April 2021).

18. Lundqvist, J.; de Fraiture, C.; Molden, D. Saving Water: From Field to Fork Curbing Losses and Wastage in the Food Chain. Available online: http:/ / www.siwi.org/documents /Resources /Policy_Briefs/CSD_More_nutrition_per_drop_2004.pdf (accessed on 18 April 2021).

19. Rosegrant, M.W.; Magalhaes, E.; Valmonte-Santos, R.A.; Mason-D'Croz, D. Returns to Investment in Reducing Postharvest Food Losses and Increasing Agricultural Productivity Growth; Copenhagen Consensus Center: Lowell, MA, USA, 2015.

20. Sheahan, M.; Barrett, C.B. Review: Food Loss and Waste in Sub-Saharan Africa. Food Policy 2017, 70, 1-12. [CrossRef]

21. Wunderlich, S.M.; Martinez, N.M. Conserving Natural Resources through Food Loss Reduction: Production and Consumption Stages of the Food Supply Chain. Int. Soil Water Conserv. Res. 2018, 6, 331-339. [CrossRef]

22. Gustavsson, J.; Cederberg, C.; Sonesson, U.; van Otterdijk, R.; Meybeck, A. Global Food Losses and Food Waste—Extent, Causes and Prevention; Food and Agricultural Organisation of the United Nations: Rome, Italy, 2011.

23. Parfitt, J.; Barthel, M.; MacNaughton, S. Food Waste within Food Supply Chains: Quantification and Potential for Change to 2050. Philos. Trans. R. Soc. B Biol. Sci. 2010, 365, 3065-3081. [CrossRef] [PubMed]

24. Lipinski, B.; Hanson, C.; Lomax, J.; Kitinoja, L.; Waite, R.; Searchinger, T. Reducing Food Loss and Waste; The Food and Agriculture Organization of the United Nations: Washington, DC, USA, 2013.

25. Neff, R.A.; Kanter, R.; Vandevijvere, S. Reducing Food Loss and Waste While Improving the Public's Health. Health Aff. 2015, 34, 1821-1829. [CrossRef]

26. Abass, A.B.; Ndunguru, G.; Mamiro, P.; Alenkhe, B.; Mlingi, N.; Bekunda, M. Post-Harvest Food Losses in a Maize-Based Farming System of Semi-Arid Savannah Area of Tanzania. J. Stored Prod. Res. 2014, 57, 49-57. [CrossRef]

27. Kantor, L.S.; Lipton, K.; Manchester, A.; Oliveira, V. Estimating and Addressing America's Food Losses. Food Rev. Natl. Food Rev. 1997, 20, 2-12. [CrossRef]

28. Scherhaufer, S.; Moates, G.; Hartikainen, H.; Waldron, K.; Obersteiner, G. Environmental Impacts of Food Waste in Europe. Waste Manag. 2018, 77, 98-113. [CrossRef]

29. Affognon, H.; Mutungi, C.; Sanginga, P.; Borgemeister, C. Unpacking Postharvest Losses in Sub-Saharan Africa: A Meta-Analysis. World Dev. 2015, 66, 49-68. [CrossRef] 
30. Bellemare, M.F.; Çakir, M.; Peterson, H.H.; Novak, L.; Rudi, J. On the Measurement of Food Waste. Am. J. Agric. Econ. 2017, 99, 1148-1158. [CrossRef]

31. Kaminski, J.; Christiaensen, L. Post-Harvest Loss in Sub-Saharan Africa-What Do Farmers Say? Glob. Food Secur. 2014, 3, 149-158. [CrossRef]

32. Lipton, M. Post-Harvest Technology and the Reduction of Hunger. IDS Bull. 1982, 13, 4-11. [CrossRef]

33. Arvanitoyannis, I.S.; Tserkezou, P. Cereal Waste Management: Treatment Methods and Potential Uses of Treated Waste. In Waste Management for the Food Industries; Elsevier: Amsterdam, The Netherlands, 2008; pp. 629-702. ISBN 9780123736543.

34. Maclean, J.; Hardy, B.; Hettel, G. Rice Almanac: Source Book for One of the Most Important Economic Activity on Earth, 4th ed.; International Rice Science Partnership: Metro Manila, Philippines, 2013.

35. Babatunde, R.; Omoniwa, A.; Aliyu, J. Post-Harvest Losses along the Rice Value Chain in Kwara State, Nigeria: An Assessment of Magnitude and Determinants. Cercet. Agron. Mold. 2019, 52, 141-150. [CrossRef]

36. Bala, B.K.; Haque, M.A.; Hossain, M.A.; Majumdar, S. Post Harvest Loss and Technical Efficiency of Rice, Wheat and Maize Production System: Assessment and Measures for Strengthening Food Security; Bangladesh Agricultural University: Bengaluru, India, 2010.

37. Coker, A.A.; Ninalowo, S.O. Effect of Post-Harvest Losses on Rice Farmers' Income in Sub-Saharan Africa: A Case of Niger State, Nigeria. J. Agric. Sci. Food Technol. 2016, 2, 27-34.

38. Danbaba, N.; Idakwo, P.Y.; Kassum, A.L.; Bristone, C.; Bakare, S.O.; Aliyu, U.; Kolo, I.N.; Abo, M.E.; Mohammed, A.; Abdulkadir, A.N.; et al. Rice Postharvest Technology in Nigeria: An Overview of Current Status, Constraints and Potentials for Sustainable Development. Open Access Libr. J. 2019, 6, 1-23. [CrossRef]

39. Sawicka, B. Post-Harvest Losses of Agricultural Produce. Sustain. Dev. 2019, 1, 1-16. [CrossRef]

40. Tefera, T. Post-Harvest Losses in African Maize in the Face of Increasing Food Shortage. Food Secur. 2012, 4, 267-277. [CrossRef]

41. Basappa, G.; Deshmanya, J.B.; Patil, B.L. Post- Harvest Losses of Maize Crop in Karnataka-An Economic Analysis. Karnataka J. Agric. Sci. 2007, 20, 69-71.

42. Ibrahim, H.I.; Saba, S.S.; Ojoko, E.A. Post Harvest Loss in Rice Production: Evidence from a Rural Community in Northern Nigeria. Fudma J. Sci. 2018, 2, 17-22.

43. Anujuprana, A.H.; Machfud; Surrisno; Suryani, A. Model for Measuring Post-Harvest Technological Capability of Paddy Farmers in Dealing with Climate Change. Innov. Syst. Des. Eng. 2013, 4, 33-43. [CrossRef]

44. Greeley, M. Food, Thchnology and Employment: The Farm-Level Post-Harvest System in Developing Countries. J. Agric. Econ. 1986, 37, 333-347. [CrossRef]

45. Qu, X.; Kojima, D.; Nishihara, Y.; Wu, L.; Ando, M. Can Harvest Outsourcing Services Reduce Field Harvest Losses of Rice in China? J. Integr. Agric. 2021, 20, 1396-1406. [CrossRef]

46. Baloch, U.K. Wheat: Post-Harvest Operations; The Food and Agriculture Organization of the United Nations: Rome, Italy; Pakistan Agricultural Research Council: Islamabad, Pakistan, 1999.

47. Taiwo, A.; Bart-Plange, A. Factors Responsible for Post-Harvest Losses and Their Effects on Rice Producing Farmers: A Case Study of Afife and Aveyime Rice Projects in the Volta Region of Ghana. Int. Res. J. Eng. Technol. 2016, 3, 1014-1022.

48. Hodges, R.J.; Bernard, M.; Rembold, F. APHLIS—Postharvest Cereal Losses in Sub-Saharan Africa, Their Estimation, Assessment and Reduction; European Union: Luxembourg, 2014.

49. Gummert, M.; Nguyen-Van-Hung; Cabardo, C.; Quilloy, R.; Aung, Y.L.; Thant, A.M.; Kyaw, M.A.; Labios, R.; Htwe, N.M.; Singleton, G.R. Assessment of Post-Harvest Losses and Carbon Footprint in Intensive Lowland Rice Production in Myanmar. Sci. Rep. 2020, 10, 19797. [CrossRef] [PubMed]

50. Alizadeh, M.R.; Allameh, A. Evaluating Rice Losses in Various Harvesting Practices. Int. Res. J. Appl. Basic Sci. 2013,4 , 894-901.

51. Amusat, M.A.; Eneh, C.K.; Obiakor, S.C. Assessment of Postharvest Losses of Rice at Different Stages of Operation. Int. J. Life Sci. 2016, 5, 50-53.

52. Li, Z.; Xia, P.; Wang, Z.; Wan, S.; He, Y. Analysis of the Constitution of Grain Postproduction Losses and the Preventive Measures. J. Zhejiang Univ. Agric. Life Sci. 1991, 17, 389-395.

53. Badawi, A.T. A Proposal on the Assessment of Rice Post-Harvest Losses. In The New Development in Rice Agronomy and Its Effects on Yield and Quality in Mediterranean Areas; (Cahiers Options Méditerranéennes; n. 58); Chataigner, J., Ed.; CIHEAM: Montpellier, France, 2001; p. 126.

54. Food and Agriculture Organization of the United Nations. Food Loss Analysis: Causes and Solutions-Case Study on the Rice Value Chain in the Democratic Republic of Timor-Leste; Food and Agriculture Organization of the United Nations: Rome, Italy, 2018.

55. Grolleaud, M. Post-Harvest Losses: Discovering the Full Story Overview of the Phenomenon of Losses during the Post-Harvest System; Food and Agriculture Organization of the United Nations: Rome, Italy, 2002.

56. Jha, S.N.; Vishwakarma, R.K.; Ahmad, T.; Rai, A.; Dixit, A.K. Assessment of Quantitative Harvest and Post-Harvest Losses of Major Crops/Commodities in India; Ministry of Food Processing Industries (Govt. of India), ICAR-Central Institute of Post-Harvest Engineering and Technology (ICAR-CIPHET): Punjab, India, 2015.

57. Nath, B.; Hossen, M.; Islam, A.; Huda, M.; Paul, S.; Rahman, M. Postharvest Loss Assessment of Rice at Selected Areas of Gazipur District. Bangladesh Rice J. 2016, 20, 23-32. [CrossRef]

58. Hasan, M.K.; Ali, M.R.; Saha, C.K.; Alam, M.M.; Haque, M.E. Combine Harvester: Impact on Paddy Production in Bangladesh. J. Bangladesh Agric. Univ. 2019, 17, 583-591. [CrossRef] 
59. Guisse, R. Post Harvest Losses of Rice (Oriza Spp) from Harvesting to Milling-A Case Study in Besease and Nobewam in the Ejisu Juabeng District in the Ashanti Region of Ghana; Kwame Nkrumah University: Kabwe, Zambia, 2010.

60. Sanneh, L. Effects of Threshing and Post-Threshing Recovery Methods on Postharvest Losses in Two Varieties of Rice; Kwame Nkrumah University: Kabwe, Zambia, 2015.

61. Greeley, M. Farm-level Post-harvest Food Losses: The Myth of the Soft Third Option. IDS Bull. 1982, 13, 51-60. [CrossRef]

62. Kitinoja, L.; Tokala, V.Y.; Brondy, A. A Review of Global Postharvest Loss Assessments in Plant-Based Food Crops: Recent Findings and Measurement Gaps. J. Postharvest Technol. 2018, 6, 1-15.

63. Kannan, E. Assessment of Pre and Post Harvest Losses of Important Crops in India; Agricultural Development and Rural Transformation Centre, Institute for Social and Economic Change: Bengaluru, India, 2014.

64. Oguntade, A.E.; Thylmann, D.; Deimling, S. Post-Harvest Losses of Rice in Nigeria and Their Ecological Footprint; GIZ: Bonn, Germany, 2014.

65. Amponsah, S.K.; Addo, A.; Dzisi, K.; Asante, B.; Afona, D. Assessment of Rice Farmers' Knowledge and Perception of Harvest and Postharvest Losses in Ghana. Cogent Food Agric. 2018, 4, 1471782. [CrossRef]

66. Appiah, F.; Guisse, R.; Dartey, P.K.A. Post Harvest Losses of Rice from Harvesting to Milling in Ghana. J. Stored Prod. Postharvest Res. 2011, 2, 64-71.

67. Ndindeng, S.A.; Candia, A.; Mapiemfu-Lamare, D.; Rakotomalala, V.; Nahemiah, D.; Kulwa, K.; Houssou, P.; Mohammed, S.; M Jarju, O.; Coulibaly, S.S.; et al. Valuation of Rice Postharvest Losses in Sub-Saharan Africa and Its Mitigation Strategies. Rice Sci. 2021, 28, 212-216. [CrossRef]

68. Sarkar, D.; Datta, V.; Chattopadhyay, K.S. Assessment of Pre and Post Harvest Losses in Rice and Wheat in West Bengal; Agro-Economic Research Centre, Visva-Bharati, Santiniketan: Santiniketan, India, 2013.

69. Bordoloi, J. Assessment of Pre and Post Harvest Losses of Paddy and Wheat in Assam; Agro-Economic Research Centre for North-East India Assam Agricultural University: Assam, India, 2013.

70. Kannan, E.; Kumar, P.; Vishnu, K.; Abraham, H. Assessment of Pre and Post Harvest Losses of Rice and Red Gram in Karnataka; Agricultural Development and Rural Transformation Centre Institute for Social and Economic Change: Bangalore, India, 2013.

71. Grover, D.K.; Singh, J.M.; Singh, P. Assessment of Pre and Post Harvest Losses in Wheat and Paddy Crops in Punjab; Agricultural Development and Rural Transformation Centre Institute for Social and Economic Change: Bangalore, India, 2012.

72. Sivagnanam, K.J. Estimation of Pre-and Post-Harvest Losses in Paddy Crop. in Tamil Nadu; Agro-Economic Research Centre, Visva-Bharati, Santiniketan: Santiniketan, India, 2013.

73. Roy, R. Assessment of Pre and Post Harvest Losses in Wheat and Paddy Crops in Uttar Pradesh; Punjab Agricultural University: Ludhiana, India, 2013.

74. Basavaraja, H.; Mahajanashetti, S.B.; Udagatti, N.C. Economic Analysis of Post-Harvest Losses in Food Grains in India: A Case Study of Karnataka. Agric. Econ. Res. Rev. 2007, 20, 117-126.

75. Veerangouda, M.; Sushilendra, S.; Prakash, K.V.; Anantachar, M. Performance Evaluation of Tractor Operated Combine Harvester. Karnataka J. Agric. Sci. 2010, 23, 282-285.

76. Gao, L.; Xu, S.; Li, Z.; Cheng, S.; Yu, W.; Zhang, Y.; Li, D.; Yu, W.; Wu, C. Main Grain Crop Postharvest Losses and Its Reducing Potential in China. Trans. Chin. Soc. Agric. Eng. 2016, 32, 1-11.

77. Wu, L.; Hu, Q.; Wang, J.; Zhu, D. Empirical Analysis of the Main Factors Influencing Rice Harvest Losses Based on Sampling Survey Data of Ten Provinces in China. China Agric. Econ. Rev. 2017, 9, 287-302. [CrossRef]

78. Gu, Y.; Sun, H.; Bi, H.; Duan, X.; Wang, J.; He, J.; Jiang, Y.; Liu, G.; Li, J. Effect of Mechanical Harvest on Rice Loss after Mature in Heilongjiang. Agric. Outlook 2020, 16, 114-118.

79. Huang, D.; Yao, L.; Wu, L.; Zhu, X. Measuring Rice Loss during Harvest in China: Based on Experiment and Survey in Five Provinces. J. Nat. Resour. 2018, 33, 1427-1438. [CrossRef]

80. Qu, X.; Kojima, D.; Nishihara, Y.; Wu, L.; Ando, M. A Study of Rice Harvest Losses in China: Do Mechanization and Farming Scale Matter? Jpn. J. Agric. Econ. 2021, 23, 83-88.

81. Alam, M.A.; Hossen, A.; Islam, A.S.; Alam, M. Performance Evaluation of Power-Operated Reapers for Harvesting Rice at Farmers' Field. J. Bangladesh Agric. Univ. 2018, 16, 144-150. [CrossRef]

82. Begum, E.A.; Hossain, M.I. Evaggelos Papanagiotou Economic Analysis of Post-Harvest Losses in Food Grains for Strengthening Food Security in Northern Regions of Bangladesh. Int. J. Appl. Res. Bus. Adm. Econ. 2012, 1, 56-65.

83. Gaiser, D. Merle Esmay Traditional Rice Harvest Loss and Labor Values in Indonesia. Trans. ASAE 1981, 24, 1162-1166. [CrossRef]

84. Boxall, R.A.; La Gra, J.; Martinez, E.; Martinez, J. Post Harvest Losses of Rice in the Dominican Republic. Trop. Stored Prod. Inf. 1981, 42, 5-10.

85. Sadiya, S.S.; Hassan, I.I. Postharvest Loss in Rice: Causes, Stages, Estimates and Policy Implications. Agric. Res. Technol. 2018, 15, 111-114. [CrossRef]

86. Kong, S.; Nanseki, T.; Chomei, Y. Farmers' Perception of Loss in Post-Harvest of Rice Yield in Cambodia. J. Fac. Agric. Kyushu Univ. 2015, 60, 569-576. [CrossRef]

87. Kebede, L.; Getnet, B.; Lema, Y.; Alebachew, M.; Ageze, M. Post-Harvest Processes and Advances to Introduce Loss-Reducing Technologies for Rice; Ethiopian Institute of Agricultural Research: Addis Ababa, Ethiopia, 2019; pp. $179-191$.

88. Wang, G.; Yi, Z.; Chen, C.; Cao, G. Effect of Harvesting Date on Loss Component Characteristics of Rice Mechanical Harvested in Rice and Wheat Rotation Area. Trans. Chin. Soc. Agric. Eng. 2016, 32, 36-42. 
89. Adeola, E.H. Post-Harvest Management Practices among Rice Farmers in Imo State Nigeria. Eur. J. Biol. Biotechnol. 2020, 1, 1-6. [CrossRef]

90. Ssebaggala, G.; Kibwika, P.; Kyazze, F..; Karubanga, G. Farmers' Perceptions of Rice Postharvest Losses in Eastern Uganda. J. Agric. Ext. 2017, 21, 30-43. [CrossRef]

91. Goldsmith, P.D.; Martins, A.G.; de Moura, A.D. The Economics of Post-Harvest Loss: A Case Study of the New Large SoybeanMaize Producers in Tropical Brazil. Food Secur. 2015, 7, 875-888. [CrossRef]

92. Isatou, J.; Sugh, E.T. Effect of Extension Dissemination on the Control of Post-Harvest Loss of Rice in West Coast Region of The Gambia. Niger. Agric. J. 2020, 51, 22-28.

93. Selvi, R.; Kalpana, R.; Rajendran, P. Pre and Post Harvest Technologies to Reduce Yield Losses in Rice-A Review. Agric. Rev. 2002, 23, 252-261.

94. Stathers, T.; Holcroft, D.; Kitinoja, L.; Mvumi, B.M.; English, A.; Omotilewa, O.; Kocher, M.; Ault, J.; Torero, M. A Scoping Review of Interventions for Crop Postharvest Loss Reduction in Sub-Saharan Africa and South Asia. Nat. Sustain. 2020, 3, 821-835. [CrossRef]

95. Zeigler, R.S.; Barclay, A. The Relevance of Rice. Rice 2008, 1, 3-10. [CrossRef] 